\title{
ARTE E FILOSOFIA: UM VÍNCULO COM A CRIATIVIDADE
}

Fernanda Soares Godoi Yano do Canto ${ }^{1}$, André Santiago Baldan ${ }^{1}$, José Antônio Leandro Filho ${ }^{1}$, Juliana de Matos Mello ${ }^{2}$, Carmen Lúcia Dias ${ }^{1}$

Universidade do Oeste Paulista - UNOESTE. ${ }^{1}$ Mestrado em Educação, Presidente Prudente - SP. ${ }^{2}$ Curso de Psicologia, Presidente Prudente -SP. E-mail: godoyfefe@gmail.com

\section{RESUMO}

Este artigo tem por objetivo apresentar reflexões de como a arte e a filosofia se complementam e intensificam o gosto e o interesse pelas diversas ramificações e conceitos que a palavra criatividade apresenta, e que quando contempladas no desenvolvimento do ser humano contribuem para a formação criativa deste indivíduo. Para atingir tal objetivo, foi utilizada como metodologia a pesquisa bibliográfica onde autores e pesquisadores desta área propõem uma discussão acerca de questões pertinentes ao espaço ocupado pelas linguagens artísticas e filosóficas nos tempos atuais. E com a contribuição desses autores, pode-se observar que o processo de criatividade faz parte do ser humano, e a arte e a filosofia se complementam para manter esse processo ativo e estimulativo.

Palavras-chave: Arte. Criatividade. Educação. Filosofia. Ser humano.

\section{ART AND PHILOSOPHY: THE RELATIONSHIP WITH CREATIVITY}

\begin{abstract}
This article has aimed to present reflections how the art and the philosophy go together and intensify the taste and the interest by the diverse ramifications and concepts that the word creativity presents, and when contemplated in the development of human being contribute to the creative formation of this individual. In order to achieve this goal, it was used as methodology the bibliographic research in which authors and researchers of this field propose a discussion about the questions concerning to the space occupied by the artistic and philosophical languages in the present times. Considering the contribution of these authors, it is possible to observe that the process of creativity is part of the human being, and the art and the philosophy go together to maintain this process active and stimulating.
\end{abstract}

Keywords: Art. Creativity. Education. Philosophy. Human being. 


\section{INTRODUÇÃO}

Desde o início da humanidade o ser humano era e é um ser muito criativo, pois o homem nasce com especificidades culturais, psicológicas e sociais, o que permite fazer ligações com a natureza e com o mundo, independendo de cultura e do desenvolvimento interno de seu ser, dessa forma, explora e estimula sua criatividade em seu cotidiano. Sans (2001, p. 24) ressalta que “A criatividade é considerada como parte essencial do homem, a qual dá equilíbrio à vida, auxiliando-o em seu cotidiano, nas resoluções de problemas e tornando o homem um ser mais criativo".

Sendo a arte e a filosofia parte integrante desse movimento que possibilita a representação e a interpretação do mundo, onde são desenvolvidas tais habilidades de seleção, classificação, identificação, entre outras, indispensáveis para organização humana.

A parceria entre a filosofia e a arte torna possível tratar com alegria e leveza alguns temas importantes e complexos da cultura e da existência, tais como o sentido da realidade, o lugar da ciência na sociedade, as interpretações do corpo e da natureza, a relação entre arte e verdade, a transitoriedade do amor e a inevitabilidade da morte. (FEITOSA, 2009, p. 8).

O filósofo Charles Feitosa $(2009$, p. 7) enfatiza que “[...] a história da filosofia é a 'nossa própria história'; afinal somos o resultado de um longo processo de errâncias". O que nos leva a pensar que toda e qualquer reflexão a respeito dos problemas sociais, será inútil se não considerarmos suas origens. "[...] A história da filosofia pode, entretanto, funcionar como uma intimidação, tolhendo nossa capacidade de pensar criativamente. Por isso o caminho que se segue coloca a prioridade nos temas e recorre à história sempre em segunda instância". (FEITOSA, 2009, p. 7-8).

A presença da história da arte também pode ser identificada em diversas manifestações, pois desde os primórdios, o homem já utilizava o desenho como uma forma de linguagem ${ }^{1}$. Pintando em suas cavernas cenas do seu cotidiano, como a caça, sua sobrevivência e as pessoas com as quais conviviam. Sousa $(2005$, p.33) menciona que "[...] muitos fatos históricos ainda hoje são evidentes e reconhecidos por meio de textos não-lingüísticos, compostos principalmente por imagens e objetos que revelam, na sua forma e no seu conteúdo, os modos de vida e as concepções de mundo de seu tempo".

Neste contexto, o referente artigo tem por objetivo apresentar reflexões de como a arte e a filosofia se complementam e intensificam o gosto e o interesse pelas diversas ramificações e

\footnotetext{
${ }^{1}$ Arte é linguagem, é conhecimento humano. Nesse contexto, desenho é uma das linguagens da arte. 
conceitos que a palavra criatividade apresenta, e que quando contempladas no desenvolvimento do ser humano contribuem para a formação criativa deste indivíduo.

\section{DESENVOLVIMENTO}

"Criatividade é característica da espécie humana. O homem criativo não é o homem comum ao qual se acrescentou algo; o homem criativo é o homem comum do qual nada se tirou".

Abraham Maslow

Observa-se que a criatividade é objeto de estudo de muitas disciplinas, como a psicologia, a sociologia, a filosofia, a história, a arte, entre outras, porém, cada uma dentro de suas especificidades, e por ter tanta ênfase, criou-se muitas polêmicas e conceitos, não somente pela complexidade de que o próprio tema aborda, mas também pela carência de precisão de limites entre as áreas de conhecimento.

A questão sobre a criatividade tornou-se eixo central das pesquisas epistemológicas, psicológicas, pedagógicas e sociológicas. E a valorização do ser humano criativo chegou a picos nunca antes atingidos. Na exploração deste conceito adentra-se no campo da educação e da psicologia. As cortinas se abrem para várias áreas de conhecimento e de orientações teóricas que permitem constatar, de imediato, a natureza dialética e interdisciplinar do conceito de criatividade. (TOMMASI, 2010, p. 26).

Desta forma, estudiosos e pesquisadores questionaram-se, quando o homem tornou-se um ser criativo? Tommasi (2010, p. 26), explicita que na "[...] tentativa de reconstruir a história da humanidade observa-se o processo criativo de cada época e cultura".

A partir do pensamento de Platão, a criatividade era amparada pela crença que a inteligência humana era orientada por uma inspiração divina. Platão afirmava que, no momento da criação, o artista perdia o controle de si mesmo, passando a um domínio de um poder superior. (Kneller, 1978).

Embasada pela ideia citada acima, a criatividade era compreendida como uma inspiração divina (um ser superior), ou ainda uma forma de insanidade, percepção ou particularidades pertencente somente aos gênios ou artistas. Wechsler (1998) em sua pesquisa, afirma que, "infelizmente, ainda encontramos, atualmente, pessoas que são altamente criativas sendo consideradas como estranhas ou meio loucas".

Segundo Silva (1999), “[...] num certo sentido, a história da criatividade confunde-se com a história da humanidade". A mesma autora alega que ainda existe certa dificuldade em definir a 
criatividade, uma vez que os termos relacionados a criatividade se confundem. E definir o que é criatividade, torna-se uma tarefa complexa, pois depende muito de quem e como a expõe.

Para a autora Tommasi, em seu texto 'Criatividade e Educação',

A criatividade não é só intelectual, nem só sentimental. Criatividade é intelectual, sentimental, visceral e dinâmica, sai das entranhas, dilacera quem cria e quem a observa, recria caminhos, oferece possibilidades.

A criatividade pura é um ato mental, que consiste em última análise da capacidade de combinar sons e imagens de forma subjetivamente nova, independentemente de qualquer conexão lógica com o mundo exterior.

Essa definição de criatividade desloca os aspectos novidade e originalidade, beleza, utilidade, veracidade, viabilidade e implementação para um segundo momento; criar é um ato pessoal e subjetivo, a criatividade pura vem antes da aplicada. Criações não tem necessariamente que servir para alguma coisa, como solucionar um problema, dar retorno financeiro, serem maravilhosas e belas, nada disso. (TOMMASI, 2010, p. 34).

Piaget (apud ANTUNES, 2003, p. 30) realça que a criatividade é sempre produto da 'abstração reflexiva' e jamais da abstração empírica, pois, enquanto esta última se limita a captar de objetos, pessoas ou conceitos a compreensão passiva da realidade, a abstração reflexiva 'consiste em destacar, das ações ou operações, novos aspectos para deles fazer elementos de uma construção nova, conferindo-Ihes uma outra organização'.

Conforme levantamento realizado pela pesquisadora Wechsler (1999), acerca da conceituação de criatividade, se valendo da contribuição de Guilford, a criatividade passa a ser abordada pelo aspecto científico, "[...] como algo que pode ser mensurável e desenvolvido, sendo entendida como um pensamento divergente, em contraste com outras formas de pensamento, como do tipo convergente". (WECHSLER, 1999, p. 28).

Existem dois tipos de abstração mental. Uma é a abstração empírica, que segundo Aristóteles ocorre quando a informação é extraída do objeto. [...] Estas noções são extraídas das suas próprias percepções, isto é, são empíricas.

[...] A abstração reflexiva, em que não se abstraí dos objetos, mas das próprias ações. Neste caso, o importante é a coordenação das ações com a origem nas próprias ações do sujeito. (PIAGET, 2001, p. 15).

Para Guilford (apud ALENCAR, 1983), os indivíduos criativos se caracterizam por pensar com maior fluência, com maior flexibilidade e com maior originalidade. Torrance (apud ALENCAR, 1983), concentra seus estudos a criatividade infantil, enfatizando os mesmos traços que Guilford, criatividade como capacidade intelectual,

[...] define a criatividade como processo de se tornar sensível a problemas, deficiências, lacunas no conhecimento; identificar a dificuldade; buscar soluções, formulando hipóteses a respeito das deficiências; testar e retestar as hipóteses, 
possivelmente modificando-as, e finalmente comunicando os resultados. (GUILFORD apud ALENCAR, 1983, p. 145).

Kneller, faz um paralelo entre o 'pensamento criador' e o 'pensamento não criador', contrastando a criatividade com a inteligência, expondo que,

[...] O pensamento criador é inovador, exploratório, aventuroso. Impaciente ante a convenção, é atraído pelo desconhecido e indeterminado. O riso e a incerteza estimulam-no. O pensamento não criador (o termo não é desairoso) é cauteloso, metódico, conservador. Absorve o novo no já conhecido e prefere dilatar as categorias existentes a inventar novas. (KNELLER, 1978, p. 19).

Alguns autores, como Guilford (apud KNELLER, 1978, p. 19-20) e Gloton, chamam de 'pensamento convergente' e 'pensamento divergente'.

O pensamento convergente é usado quando o problema requer solução única e imediata, muito estruturada, comportando dados rigorosos. [...] É um tipo de pensamento conformista, prudente, rigoroso, mas estreito. É a forma de atuar da inteligência com as informações, a memória etc.

O pensamento divergente é o de quem, ante um problema, busca todas as soluções possíveis e tende mais para a originalidade do que para o conformismo na resposta, gosta de situações complexas e mal definidas, percebe relações entre fatos nunca relacionados até então. Esse tipo de pensamento caracteriza o espírito de aventura e de fantasia. (GLOTON, apud CASTANHO, 2000, p. 84-85).

Entretanto, ambos os pensamentos são importantes e complementares entre si, uma vez que, o pensamento divergente só ocorrerá se puder utilizar a memória; a informação depende principalmente do pensamento convergente. Nesse sentido, para melhor desenvolvimento da inteligência é imprescindível os dois tipos de pensamento. Gloton (apud CASTANHO, 2000, p. 85), grifa que, "[...] é preciso pensar uma 'pedagogia da divergência' para evitar o bloqueio da criatividade".

Atualmente, ainda não conseguiram chegar a uma consonância sobre o que é criatividade, observa-se distintas definições e conceituações, uma vez que, nenhuma resposta é completa, pois cada uma omite e/ou é complementar a outra.

Todos esses autores e pesquisadores salientam e evidenciam em seus trabalhos a importância da criatividade para o pleno desenvolvimento do ser humano. O que se sabe é que todo ser humano, em grande ou pequena proporção, é criativo, e que um ambiente estimulador beneficia o aumento da criatividade nos indivíduos. 


\section{DISCUSSÃO/CONCLUSÃO}

Podemos observar, por meio dos aportes dos autores, que o processo de criatividade faz parte do ser humano e, a arte e a filosofia se complementam para manter esse processo ativo e estimulativo. Tais experiências estimuladoras da criatividade implicam no desenvolvimento das relações e das descobertas pessoais de cada um, uma vez que a criatividade e as linguagens artísticas e filosóficas existem nas relações do indivíduo e seu meio.

Portanto, a arte e a filosofia intensifica o gosto e o interesse pelas diversas ramificações e conceitos deste universo fascinante que é a criatividade. E que por meio delas, construiremos uma sociedade mais sensível, onde cada ser humano seja capaz de valorizar e dar voz uns aos outros.

Consideramos importante a publicação deste artigo porque nos articula com profissionais e pesquisadores que está a mais tempo produzindo neste campo, abre espaços de diálogo com outras produções, tornando-se mais abrangente seu raio de ação, para uma pesquisa científica, e nos coloca abertos a críticas e novas contribuições.

\section{REFERÊNCIAS}

ALENCAR, E. M. L. S. Psicologia: introdução aos princípios básicos do comportamento. 5. ed. Petrópolis, Rio de Janeiro: Vozes, 1983.

ANTUNES, C. A criatividade na sala de aula. Fascículo 14. 4. ed. Petrópolis, Rio de Janeiro: Vozes, 2003.

CASTANHO, M. E. A criatividade na sala de aula universitária. In: VEIGA. I. P. A. CASTANHO, M. E. (Org.). Pedagogia universitária: a aula em foco. São Paulo: Papirus, 2000.

FEITOSA, Charles. Explicando a Filosofia com Arte. Rio de Janeiro: Ediouro. 2009.

KNELLER, G. F. Arte e ciência da criatividade. Tradução de J. Reis. 5. ed. São Paulo: IBRASA, 1978.

PIAGET, J. Criatividade. In: VASCONCELOS, M. S. (Org.). Criatividade: psicologia, educação e conhecimento do novo. São Paulo: Moderna, 2001.

SANS, P. T. C. Pedagogia do desenho infantil. São Paulo: Átomo, 2001.

SILVA, M. F. M. Definição e avaliação da criatividade: contributos da abordagem cognitiva. Tese de Doutorado. Instituto de Educação e Psicologia, da Universidade do Minho. Minho, Portugal. 1999.

SOUSA, R. P. L. de. Roteiro didático da arte na produção do conhecimento. Campo Grande, MS: Ed. UFMS, 2005.

TOMMASI, S. M. B. Arte e Criatividade (Parte 1). Revista Direcional, jun. 2010, p. 26-27. 
WECHSLER, S. M. Criatividade, descobrindo e encorajando. Campinas: Livro Pleno. 1998. 